\title{
Physicochemical Properties and Bacterial Communities of Meongge (Halocynthia roretzi) Jeotgal Prepared with 3 Different Types of Salts ${ }^{\mathrm{S}}$
}

\author{
Jeong A Kim ${ }^{1}$, Zhuang $\mathrm{Yao}^{1}$, Hyun-Jin Kim ${ }^{1,2}$, and Jeong Hwan Kim ${ }^{1,2 *}$ \\ ${ }^{1}$ Division of Applied Life Science (BK21 Plus), Graduate School, Gyeongsang National University, Jinju 52828, Republic of Korea \\ ${ }^{2}$ Institute of Agriculture and Life Science, Gyeongsang National University, Jinju 52828, Republic of Korea
}

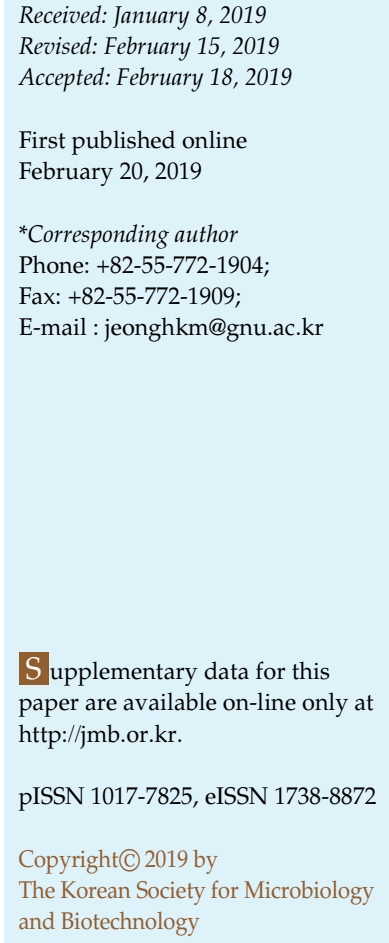

Three types of meongge (Halocynthia roretzi) jeotgal (MJ) were prepared with 3 different types of salts (12\%, w/v): purified salt (PS), solar salt aged for 3 years (SS), and bamboo salt that had been recrystalized 3 times (BS). One set of MJ was fermented with starters, Bacillus subtilis JS2 and Tetragenococcus halophilus BS1-37 (each $6 \log$ CFU/g), and another set without starters for 42 days at $10^{\circ} \mathrm{C}$. The LAB count of the SSMJ (non-starter) was highest at day $28(2.30 \log \mathrm{CFU} / \mathrm{g}$ ). The $\mathrm{pH}$ of the PSMJ and SSMJ was 5.72-5.77 at day 0, and 5.40-5.50 at day 42. BSMJ showed higher $\mathrm{pH}$ and lower titratable acidities than other samples. Amino-type nitrogen (ANN) increased continuously, and SSMJ showed higher values than other samples from day 14 . Bacterial species of non-starter MJ were examined by culture independent method. Clone libraries of $16 \mathrm{~S}$ rRNA genes were constructed in Escherichia coli from total DNA from nonstarter MJ samples at day 0,14, and 28. Thirty clones per each sample were randomly selected and DNA sequences were analyzed. Variovorax sp., uncultured bacterium, and Acidovorax sp. were the most dominant group at day 0, 14, and 28, respectively. Lactobacillus sakei and Streptococcus sp. were the next dominant group in SSMJ at day 28. A Streptococcus sp. was detected from PSMJ at day 28. Sensory evaluation for MJ samples at day 28 showed that SSMJ got higher overall acceptability scores. These results showed that solar salt can cause desirable changes in the microbial community of fermented foods, thereby positively affecting their overall quality.

Keywords: Meongge jeotgal, bacterial community, solar salt, LAB

\section{Introduction}

Meongge or common sea squirt (Halocynthia roretzi), is a popular seafood in Korea because of its unique flavor and taste. It is commercially grown on a large scale along the southern coastal regions of the Korea peninsula. Cultivated meongge is harvested during the spring season and the fleshy part inside the hard skin is consumed without further processing. Although its unique flavor and taste enable its raw consumption, development of processed products is desirable to increase its year-round sale and commercial value [1, 2]. For this purpose, jeotgal and sikhae (fermented fish) have been prepared from meongge, and the changes in nutrients and taste during fermentation were reported [2,3]. However, no studies have been done on the microorganisms during meongge jeotgal (MJ) fermentation. In addition, no studies have been done on the effects of salts on MJ fermentation. Salt is an essential ingredient for fermented foods, including jeotgal, where a large amount of salt $(20-30 \%, \mathrm{w} / \mathrm{w})$ is added to prevent putrefaction [4]. Different types of salts such as purified salt, solar salt and bamboo salt are used for fermented foods including kimchi, soybean paste, and jeotgal [5-7]. But the effects of salt types on the quality of fermented foods are not well understood. Especially, the effects of salt types on the growth of microorganisms during 
fermentation processes are rarely studied although salt types affect microbial communities, which in turn affect the quality of fermented foods [7, 8]. For the production of high quality fermented foods, the fermentation conditions should be optimized for each type of food, including the concentration and type of salt, use of suitable starters, and temperature. In this work, MJ samples $(12 \% \mathrm{NaCl}, \mathrm{w} / \mathrm{w})$ were prepared with 3 different salts; purified salt (PS), 3year-old solar salt (SS), and bamboo salt (BS, $\left.3^{\text {rd }}\right)$. MJ samples were fermented for 42 days at $10^{\circ} \mathrm{C}$. The growth of bacilli and lactic acid bacteria (LAB) were examined together with other properties during fermentation. Bacterial communities were analyzed by a culture-independent method. The results obtained through this work might be useful as basic data for the preparation of MJ with high quality.

\section{Materials and Methods}

\section{Preparation of MJ Samples}

Meongge (sea squirt, Halocynthia roretzi) was purchased from a local fish market (Korea) in February 2018. Immediately after purchase, the meongge was washed under running tap water, and left standing for $10 \mathrm{~min}$ to remove excess water. Each $2.0 \mathrm{~kg}$ of meongge was mixed with salt. $\mathrm{NaCl}$ concentration was adjusted to $12 \%(\mathrm{w} / \mathrm{w})$ by adding different amounts of each salt: $275.86 \mathrm{~g}$ for purified salt (PS, Hanju, Korea, 2017, $\mathrm{NaCl}$ 99\%); $324.19 \mathrm{~g}$ for solar salt aged for 3 years (SS, Taepyung salt farm, Sinan, Korea, NaCl $86.03 \%) ; 290.77 \mathrm{~g}$ for bamboo salt (BS, Insanga, Korea, melted and recrystallized 3 times, $\mathrm{NaCl} 94.54 \%$ ). For one set of $\mathrm{MJ}$ samples, Bacillus subtilis JS2 and Tetragencoccus halophilus BS1-37 were inoculated at each $6 \log \mathrm{CFU} / \mathrm{g}$ (starter MJ). Another set of MJ samples were prepared without starters (non-starter MJ). All $6 \mathrm{MJ}$ samples were fermented for 42 days at $10^{\circ} \mathrm{C}$ and analyzed every 7 days during fermentation.

\section{Viable Cell Counting}

Twenty gram of MJ sample was mixed with $20 \mathrm{ml}$ of peptone water $(0.1 \%, \mathrm{w} / \mathrm{v})$ and homogenized using a Stomacher 80 (Seward, USA). Homogenate was filtered with a bag filter (3M, $19 \times 30$, USA) and diluted serially with peptone water. Diluted samples were spread on lactobacilli MRS agar (Difco, USA) plates for lactic acid bacteria (LAB) counting, Luria-Bertani (LB) agar (BD Biosciences, USA) plates for bacilli counting, and yeast-mold (YM, BD Biosciences) agar plates for yeast counting. Plates were incubated for $72 \mathrm{~h}$ at $37^{\circ} \mathrm{C}$ for bacilli, and $120 \mathrm{~h}$ at $30^{\circ} \mathrm{C}$ for $\mathrm{LAB}$ and yeasts.

\section{pH and Titratable Acidity (TA)}

Ten grams of homogenized MJ sample was mixed with $40 \mathrm{ml}$ of distilled water, and shaken for $1 \mathrm{~h}$ in a water bath $\left(150 \mathrm{rpm}, 30^{\circ} \mathrm{C}\right)$. Supernatant was obtained after centrifugation $(4,000 \times \mathrm{g}, 20 \mathrm{~min}$, $4^{\circ} \mathrm{C}$ ). The $\mathrm{pH}$ of the supernatant was measured using a $\mathrm{pH}$ meter
(DP-215M, DMS, Korea). Titratable acidity (TA) was calculated by titrating supernatant with $0.1 \mathrm{~N} \mathrm{NaOH}$ until $\mathrm{pH}$ 8.4. The amount of $\mathrm{NaOH}$ was used to calculate the amount of lactic acid (\%).

\section{Amino-Type Nitrogen (ANN), Ammonia-Type Nitrogen (AMN) and Volatile Basic Nitrogen (VBN)}

ANN, AMN, and VBN of MJ samples were measured during fermentation according to methods described previously [7].

\section{Moisture Content and Salinity}

Moisture content of homogenized MJ sample was measured by using an infrared moisture analyzer (MX-50, AND, Japan). For salinity measurements, $10 \mathrm{~g}$ of homogenized MJ sample was mixed with $40 \mathrm{ml}$ of distilled water. Supernatant was obtained after shaking in a water bath and centrifugation as stated above. Salinity of supernatant was measured by using a salt-meter (PALSALT, Atago, Japan). Measurements were repeated 3 times and the average values were shown.

\section{Bacterial Communities of Non-Starter MJ Samples}

Non-starter MJ samples were collected at day 0, 14, and 28. Total DNA was extracted by using a EZ-10 Spin Column Soil DNA Miniprep Kit (Bio Basic Inc., Canada). 16S rRNA genes were amplified from the extracted DNA samples by using universal primer pair, 27F (5'-AGAGTTTGATCMTGGCTCAG-3') and 1492R (5'-GGY TACCTTACGACTT-3'). PCR was done under the following conditions: denaturation at $94^{\circ} \mathrm{C}$ for $5 \mathrm{~min}, 40$ cycles of $30 \mathrm{sec}$ at $94^{\circ} \mathrm{C}, 2 \mathrm{~min}$ at $57^{\circ} \mathrm{C}$, and $2 \mathrm{~min}$ at $72^{\circ} \mathrm{C}$, and a final extension at $72^{\circ} \mathrm{C}$ for $7 \mathrm{~min}$. Amplified fragments were purified by using a FavorPrep PCR Purification Kit (Favorgen, Taiwan) and ligated with pGEM-T easy vector (Promega, USA). Escherichia coli DH5 $\alpha$ competent cells (Enzynomics, Korea) were transformed with the ligation mixture, and transformants were selected on LB plates with ampicillin $(100 \mu \mathrm{g} / \mathrm{ml})$, isopropyl $\beta$-D-1-thiogalactopyranoside (500 $\mu \mathrm{g} / \mathrm{ml})$, and 5-bromo-4-chloro-3-indolyl- $\beta$-D-galactopyranoside $(80 \mu \mathrm{g} / \mathrm{ml})$. Thirty colonies were selected randomly from each MJ sample, and their inserts were sequenced. DNA sequencing was done at Cosmogenetech (Korea), and BLAST was used to find homologous sequences in the data library (http://www.ncbi.nlm. nih.gov/BLAST).

\section{Sensory Evaluation}

Sensory evaluation for MJ samples at day 28 was done by 21 tasters (male:female $=8: 13$, average age, 25.7 years) using a 5point scale for color, flavor, taste, texture, saltiness, sourness, bitterness, fishy smell, umami and overall acceptability. The properties were evaluated as follows: very poor (1 point), medium ( 3 points), and very good (5 points). Tasters were provided with drinking water and crackers to rinse their mouths and remove any aftertaste before testing other samples. The statistical analyses of sensory data were performed by least significant difference (LSD) test $(p<0.005)$. 


\section{Results and Discussion}

\section{Viable Cell Counting}

Viable cells of bacilli, LAB and yeasts were counted every 7 days during 42 days of fermentation and the results are shown in Fig. 1 and Fig. 2. Yeasts were not detected during the entire fermentation period. Bacilli and LAB counts of starter MJ samples decreased gradually from day 0 (immediately after preparation) until day 42 . The initial bacilli counts were 6.56-6.87 $\log \mathrm{CFU} / \mathrm{g}$ and the final counts were 5.61-5.83 log CFU/g, one log reduction during fermentation. LAB counts decreased in a similar way but decreased more, the initial counts of 6.19-6.40 log CFU/g decreased to 4.71-4.79 $\log \mathrm{CFU} / \mathrm{g}$ at day 42 (Fig. 1). Considering the inoculum size of $B$. subtilis JS2 and T. halophilus BS1-37 (each $6 \log \mathrm{CFU} / \mathrm{g}$ ), the results indicated that added starters did not grow well under the fermentation conditions $\left(10^{\circ} \mathrm{C}\right.$ and $\left.12 \% \mathrm{NaCl}(\mathrm{w} / \mathrm{w})\right)$ although significant
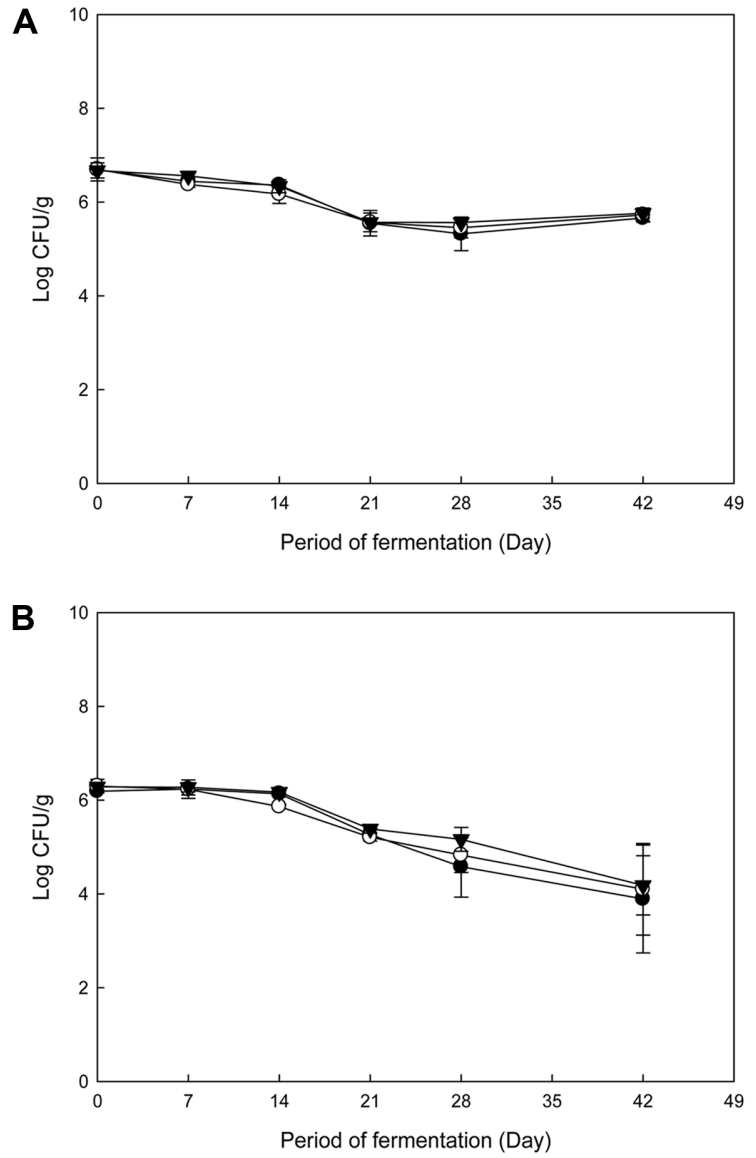

Fig. 1. Bacilli (A) and LAB (B) viable counts of starter MJ samples during fermentation.

, starter MJ with purified salt; $\bigcirc$, starter MJ with solar salt; starter MJ with bamboo salt. portions of starter cells survived. In previous studies, B. subtilis JS2 grew up to $20 \% \mathrm{NaCl}(\mathrm{w} / \mathrm{v})$ in LB broth [9] and T. halophilus BS1-37 grew up to $23 \% \mathrm{NaCl}(\mathrm{w} / \mathrm{v})$ in lactobacilli MRS broth [10]. MJ fermentation conditions used for this work, especially low temperature $\left(10^{\circ} \mathrm{C}\right)$ combined with relatively high salt concentration, were not good for the growth of starters. MJ samples prepared with different salt types did not show significant differences in bacilli and $\mathrm{LAB}$ viable counts.

Bacilli counts of non-starter MJ samples were 4.07-5.15 $\log \mathrm{CFU} / \mathrm{g}$ at day 0, and decreased during fermentation (Fig. 2). Bacilli counts of PSMJ and SSMJ samples decreased rapidly during the first week and the counts were 2.77$2.82 \log \mathrm{CFU} / \mathrm{g}$, the lowest counts, at day 7. BSMJ showed the lowest count $(2.74 \log \mathrm{CFU} / \mathrm{g})$ at day 21. After the lowest points, bacilli counts increased slowly and reached to 4.20-4.64 $\log \mathrm{CFU} / \mathrm{g}$ at day 42. The final counts were either slightly higher than initial counts for PSMJ and BSMJ
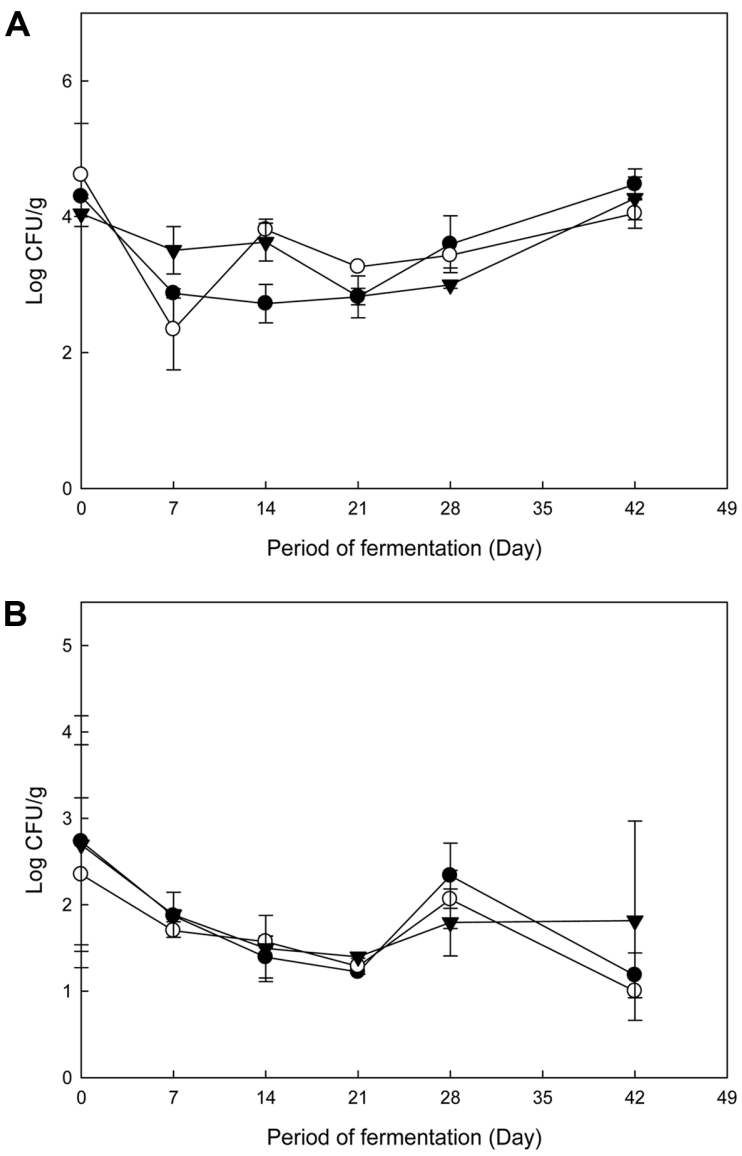

Fig. 2. Bacilli (A) and LAB (B) viable counts of non-starter MJ samples during fermentation.

, non-starter MJ with purified salt; $\bigcirc$, non-starter MJ with solar salt; $\boldsymbol{\nabla}$, non-starter MJ with bamboo salt. 
samples or 1 log reduced for SSMJ. LAB counts of nonstarter MJ samples were 2.98-3.76 log CFU/g at day 0 and gradually decreased during fermentation. The final LAB counts were $1 \log \mathrm{CFU} / \mathrm{g}$. The final LAB counts of nonstarter MJ samples were 5,000 times on average lower than those of starter MJ samples, whereas the final bacilli counts of non-starter MJ samples were 10 times lower than those of starter MJ samples. No significant differences in bacilli and LAB counts were observed among non-starter MJ samples.

\section{pH and Titratable Acidity (TA)}

$\mathrm{pH}$ and TA values of MJ samples during fermentation are shown in Fig. 3. Immediately after preparation, $\mathrm{pH}$ of
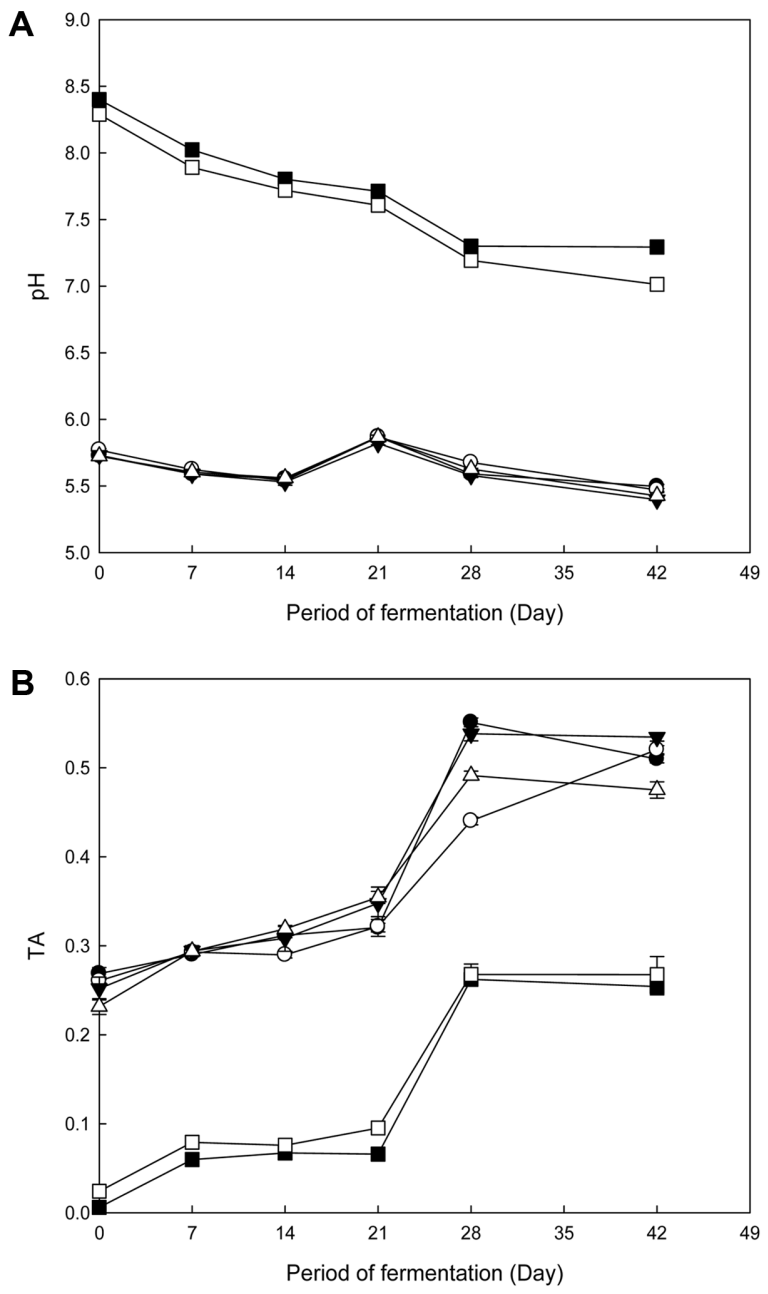

Fig. 3. $\mathrm{pH}(\mathbf{A})$ and titratable acidity (B) of MJ samples during fermentation.

, starter MJ with purified salt; $\bigcirc$, non-starter MJ with purified salt; $\boldsymbol{\nabla}$, starter MJ with solar salt; $\triangle$, non-starter MJ with solar salt; starter MJ with bamboo salt; $\square$, non-starter MJ with bamboo salt.
PSMJ and SSMJ samples were 5.72-5.77, and pH decreased slowly until day 14 (5.53-5.56), then increased rapidly until day 21 (5.82-5.87) (Fig. 3A). After day 21, pH again decreased gradually, reaching to 5.40-5.50 at day 42 . The final $\mathrm{pH}$ values were lower than those of the initial values by $0.2-0.3$. BSMJ had much higher $\mathrm{pH}$ values of $8.40 \pm 0.02$ (starter) and $8.29 \pm 0.01$ (non-starter) at day 0. This was due to the high mineral content of BS. BS contains a large amount of $\mathrm{K}, \mathrm{Si}, \mathrm{Fe}$, and $\mathrm{PO}_{4}$ and its aqueous solution is alkaline ( $\mathrm{pH}$ 10) [11]. Unlike other MJ samples, $\mathrm{pH}$ of the BSMJ samples decreased continuously throughout the fermentation period, and the final $\mathrm{pH}$ was 7.29 for starter and 7.01 for non-starter BSMJ. BSMJ (starter and non-starter) showed higher $\mathrm{pH}$ values throughout the fermentation period. At day 42, pH of PSMJ was 5.50 for starter and 5.47 for non-starter. $\mathrm{pH}$ of SSMJ was 5.40 for starter and 5.43 for non-starter. Starter SSMJ showed the lowest $\mathrm{pH}$ value.

TA values of PSMJ and SSMJ samples were 0.23-0.27, but just 0.01-0.02 for BSMJ at day 0 (Fig. 3B). TA values of all MJ samples increased gradually until day 21 , and then rapidly increased until day 28. After day 28, TA values either increased or decreased slightly. At day 42, TA was 0.25 for starter and 0.27 for non-starter BSMJ. TA of PSMJ was 0.51 for starter and 0.52 for non-starter, and TA of SSMJ was 0.53 for starter and 0.48 for non-starter. Starter PSMJ and SSMJ showed the highest TA values. $\mathrm{pH}$ and TA values of jeotgal samples reflect the amounts of organic acids such as lactic acid produced by microorganisms during fermentation $[12,13]$.

\section{ANN, AMN, and VBN Content}

Amino-type nitrogen (ANN) of MJ samples were measured during fermentation (Fig. 4A). ANN is related to the degree of protein hydrolysis of raw materials [14]. Proteins in the raw materials are hydrolyzed by proteolytic enzymes either from microorganisms or raw materials into peptides and amino acids, causing the development of unique physical properties, flavor, and aroma of fermented foods [15]. The ANN was $118.53-145.47 \mathrm{mg} \%$ at day 0 , immediately after preparation. ANN of all MJ samples increased rapidly during fermentation. As expected, starter MJ showed higher values than non-starter MJ. The starters (Bacillus subtilis JS2 and Tetragenococcus halophilus BS1-37) possess strong proteolytic activities. Starter SSMJ showed the highest values from day 14 until day 42, $257.12 \pm$ $4.19 \mathrm{mg} \%$ at day 42 . BSMJ showed the lowest values until day 28 (203.14-209.86 mg\% at day 28). But after day 28, the ANN values increased rapidly, and were same as in other MJ samples at day 42 . 

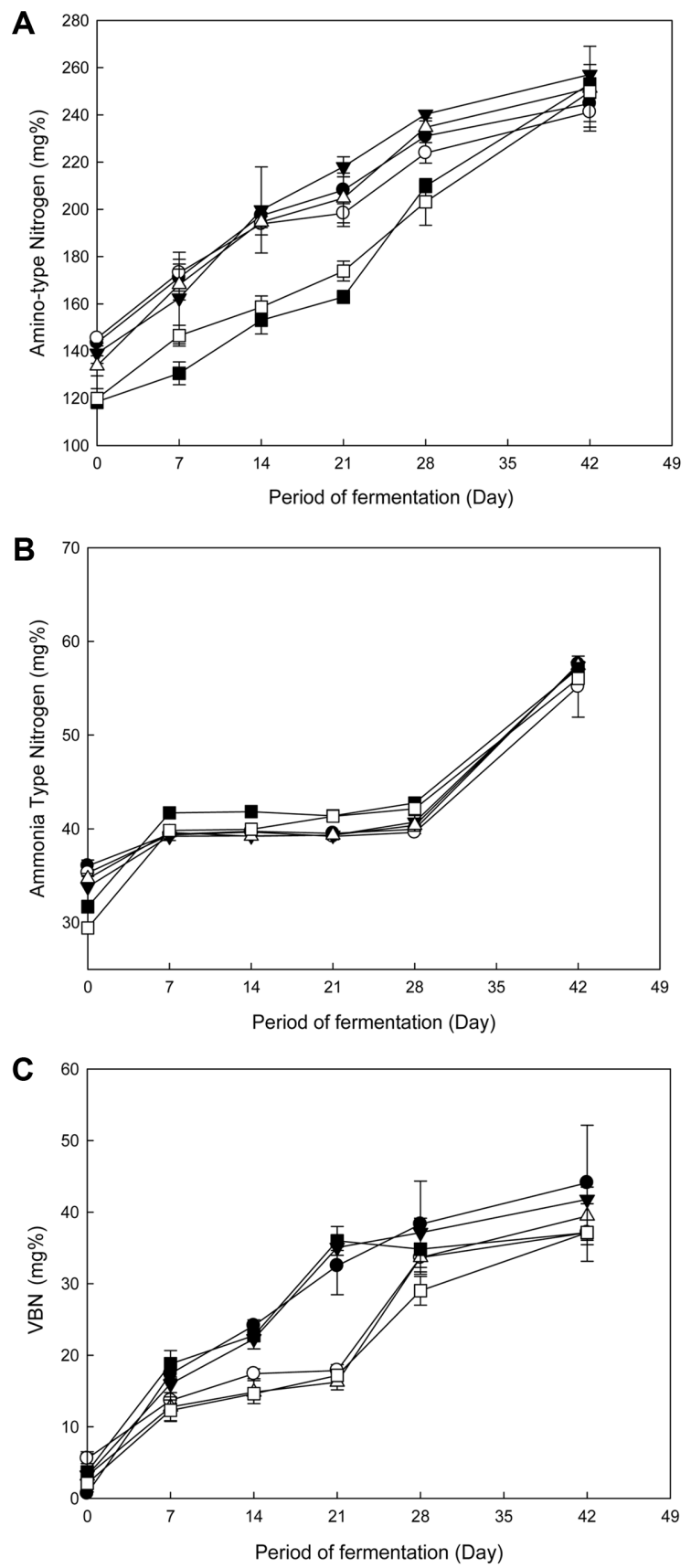

Fig. 4. Amino-type nitrogen (A), ammonia-type nitrogen (B), and volatile basic nitrogen (C) of MJ samples during fermentation.

-, starter MJ with purified salt; $\bigcirc$, non-starter MJ with purified salt; $\boldsymbol{\nabla}$, starter MJ with solar salt; $\triangle$, non-starter MJ with solar salt; starter MJ with bamboo salt; $\square$, non-starter MJ with bamboo salt.

The delicate flavors of fermented foods are developed as proteins are hydrolyzed into peptides and amino acids. However, if excessive decomposition occurs, strongly volatile and unpleasant ammonia-type nitrogens are generated, causing a negative effect. But ammonia-type nitrogen also serves as a fermentation index of fermented foods. The AMN levels of MJ during fermentation are shown in Fig. 4B. The AMN levels of starter MJ were 31.49-57.83 mg\%, and those of non-starter MJ were 29.28$57.94 \mathrm{mg} \%$ at day 0 . AMN increased rapidly until day 7 , then did not change until day 28, and then increased rapidly again until day 42 . BSMJ showed higher AMN than other MJ samples until day 28. The AMN levels of starter MJ were not different significantly from those of nonstarter MJ.

Volatile basic nitrogen (VBN) levels of MJ were measured (Fig. 4C). VBN represents lower basic nitrogen compounds with volatility, such as various basic amines including ammonia and trimethylamine, and the value is used for assessing the freshness of foods [16]. VBN levels of MJ were $0.70-6.27 \mathrm{mg} \%$ at day 0. All MJ samples showed steady increases from day 0 until day 42. Especially, VBN levels of starter MJ samples increased rapidly compared to those of non-starter MJ samples. PSMJ showed the highest value at day 28 (starter $38.31 \pm 6.03$, non-starter $33.67 \pm$ 2.01). BSMJ showed the lowest value from day 28 until the end of fermentation.

\section{Moisture Content and Salinity}

The moisture content of MJ samples at day 0 was $73.99-76.35 \%$ (Fig. 5A). Raw meongge contains more than 80\% moisture (https://www.nifs.go.kr/page?id=aq_seafood_ 2_7\&type=tot\&from=totList\&fim_col_id=2009-MF00085266-D01). The result showed that some water loss occurred due to added salt. In a previous report, the moisture content of $\mathrm{MJ}$ with $8 \% \mathrm{NaCl}$ was $75.10 \pm 0.2 \%$ [17]. Our results are quite similar with that report.

The initial salinities of MJ samples were not constant but became constant as fermentation proceeded (Fig. 5B). Salinities of BSMJ (non-starter) were higher than other samples until day 21 (12.53-13.43\%). Salinities of MJ samples were fluctuated until day $21(11.35-13.43 \%)$ and then became stabilized from day 28 (11.98-12.70\%). At day 42 , non-starter and starter BSMJ showed higher salinities than other MJ, and the value was $12.40 \pm 0.36 \%$ for nonstarter and $12.33 \pm 0.55 \%$ for starter BSMJ.

\section{Bacterial Communities of Non-Starter MJ Samples}

Thirty clones of each clone library were sequenced and about 800 nucleotide sequences were analyzed by BLAST for identification. Variovorax sp. was the most dominant group in non-starter MJ samples at day 0, occupying 30\%, 

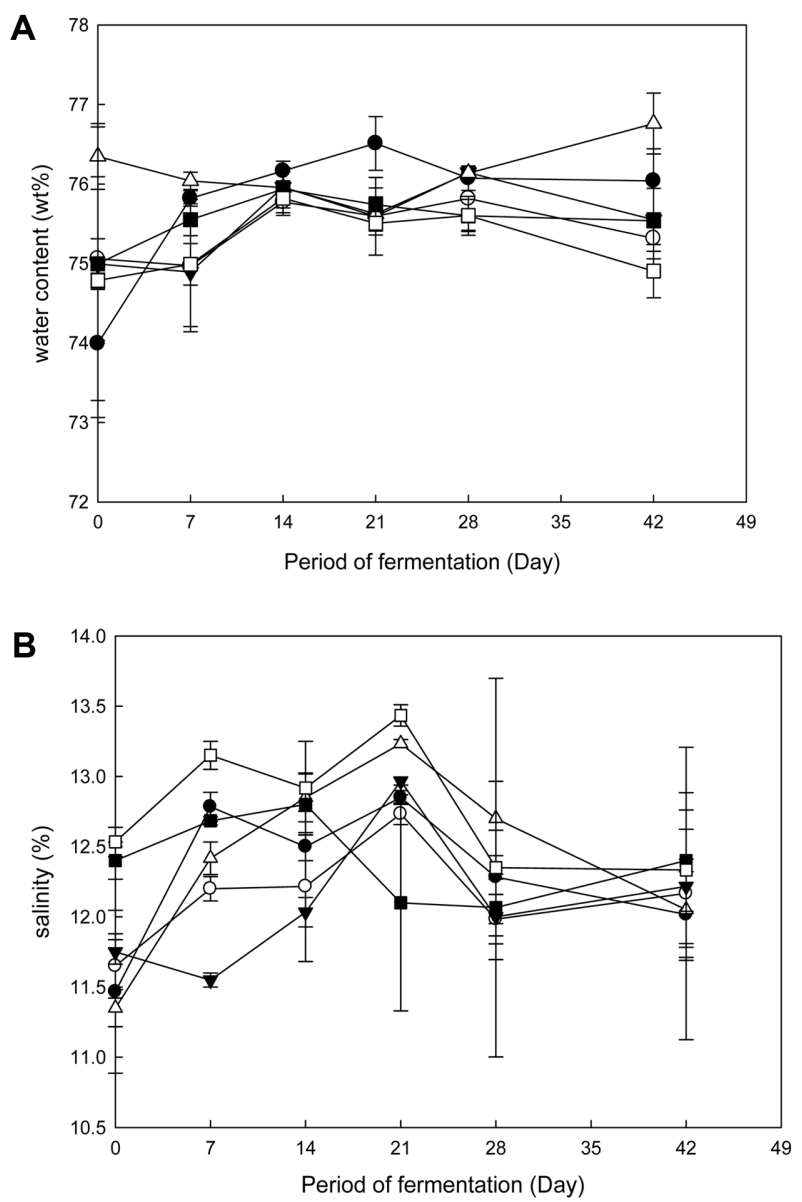

Fig. 5. Moisture content (A) and salinity (B) of MJ samples during fermentation.

- starter MJ with purified salt; $\bigcirc$, non-starter MJ with purified salt; $\boldsymbol{\nabla}$, starter MJ with solar salt; $\triangle$, non-starter MJ with solar salt; starter MJ with bamboo salt; $\square$, non-starter MJ with bamboo salt.

$46.7 \%$ and $40 \%$ of PSMJ (9 out of 30 ), SSMJ (14 out of 30 ) and BSMJ (12 out of 30) clone library, respectively (Table 1). Variovorax is a genus belonging to the family of Comamonadaceae, gram negative, motile, and widely present in various environments of soil and water including ocean sediment near the Arctic [18, 19]. They possess diverse metabolic capacities and are considered promising organisms for bioremediation [20]. Variovorax sp. were likely to be originated from sea squirt since day 0 was just after preparation of MJ samples. Since some Variovorax sp. are known to tolerate $\mathrm{NaCl}$ up to 3-5\%, and the $\mathrm{NaCl}$ concentration of MJ samples was $12 \%$, Variovorax sp. were unlikely to grow in MJ samples [21]. This seemed the reason of reduced detection of Variovorax sp. at day 14 and no detection at day 28 (Tables 2 and 3). Acidovorax sp.
Table 1. Identification of clone library prepared from nonstarter MJ (0 day).

\begin{tabular}{|c|c|c|c|}
\hline Sample & $\begin{array}{l}\text { 16S rRNA gene sequence* } \\
\text { (NCBI Accession No.) }\end{array}$ & $\begin{array}{c}\text { Similarity } \\
(\%)\end{array}$ & $\begin{array}{c}\text { Clone } \\
\text { numbers } \\
\text { out of } 30 \\
(\%)\end{array}$ \\
\hline \multirow{14}{*}{ PS } & Variovorax sp. (MH698893.1) & $99 \%$ & $8(26.7 \%)$ \\
\hline & Variovorax sp. (LC040880.1) & $99 \%$ & $1(3.3 \%)$ \\
\hline & Acidovorax sp. (MH512862.1) & $99 \%$ & $6(20.0 \%)$ \\
\hline & Burkholderia cepacia (LC420066.1) & $99 \%$ & $4(13.3 \%)$ \\
\hline & Bradyrhizobiaceae bacterium (AY429694.1) & $98 \%$ & $2(6.7 \%)$ \\
\hline & Burkholderia sp. (CР029825.1) & $100 \%$ & $1(3.3 \%)$ \\
\hline & Burkholderia cepacia (LC420066.1) & $99 \%$ & $1(3.3 \%)$ \\
\hline & Rhodopseudomonas sp. (MG798777.1) & $93 \%$ & $1(3.3 \%)$ \\
\hline & Methylobacterium sp. (MH686068.1) & $99 \%$ & $1(3.3 \%)$ \\
\hline & Bradyrhizobium sp. (MG798777.1) & $99 \%$ & $1(3.3 \%)$ \\
\hline & Ralstonia sp. (LC385700.1) & $99 \%$ & $1(3.3 \%)$ \\
\hline & Ralstonia pickettii (СР001645.1) & $99 \%$ & $1(3.3 \%)$ \\
\hline & Uncultured bacterium (MH252192.1) & $99 \%$ & $1(3.3 \%)$ \\
\hline & Uncultured bacterium (HM141889.1) & $99 \%$ & $1(3.3 \%)$ \\
\hline \multirow[t]{7}{*}{ Total } & 30 & & \\
\hline & Variovorax sp. (MH698893.1) & $99 \%$ & $7(23.3 \%)$ \\
\hline & Variovorax sp. (EU057880.1) & $98 \%$ & $2(6.7 \%)$ \\
\hline & Variovorax sp. (GQ478274.1) & $99 \%$ & $1(3.3 \%)$ \\
\hline & Variovorax sp. (LC040880.1) & $99 \%$ & $1(3.3 \%)$ \\
\hline & Variovorax boronicumulans (MH929813.1) & $99 \%$ & $1(3.3 \%)$ \\
\hline & Variovorax boronicumulans (MH211313.1) & $100 \%$ & $1(3.3 \%)$ \\
\hline \multirow{8}{*}{ SS } & Variovorax paradoxus (GU186109.1) & $99 \%$ & $1(3.3 \%)$ \\
\hline & Acidovorax sp. (MH512862.1) & $100 \%$ & $4(13.3 \%)$ \\
\hline & Burkholderia cepacia (LC420066.1) & $99 \%$ & $6(20.0 \%$ \\
\hline & Comamonas sp. (MH698867.1) & $100 \%$ & $1(3.3 \%)$ \\
\hline & Comamonas sp. (MG561176.1) & $98 \%$ & $1(3.3 \%)$ \\
\hline & Burkholderia lata (СР013406.1) & $100 \%$ & $2(6.7 \%)$ \\
\hline & Burkholderia cenocepacia (KF475841.1) & $100 \%$ & $1(3.3 \%)$ \\
\hline & Uncultured bacterium (JX225058.1) & $98 \%$ & $1(3.3 \%)$ \\
\hline \multirow[t]{7}{*}{ Total } & 30 & & \\
\hline & Variovorax sp. (MH698893.1) & $100 \%$ & $11(36.7 \%)$ \\
\hline & Variovorax sp. (LC040880.1) & $100 \%$ & $1(3.3 \%)$ \\
\hline & Acidovorax sp. (MH512862.1) & $100 \%$ & $5(16.7 \%)$ \\
\hline & Acidovorax sp. (KT354276.1) & $99 \%$ & $1(3.3 \%)$ \\
\hline & Uncultured bacterium (JN820216.1) & $99 \%$ & $1(3.3 \%)$ \\
\hline & Uncultured bacterium (KF515167.1) & $99 \%$ & $2(6.7 \%)$ \\
\hline \multirow[t]{7}{*}{ BS } & Uncultured bacterium (KR110096.1) & $99 \%$ & $2(6.7 \%)$ \\
\hline & Uncultured bacterium (HM141889.1) & $99 \%$ & $1(3.3 \%)$ \\
\hline & Burkholderia lata (СР013406.1) & $100 \%$ & $2(6.7 \%)$ \\
\hline & Bradyrhizobium sp. (AB681389.1) & $99 \%$ & $1(3.3 \%)$ \\
\hline & Bradyrhizobium elkanii (FN178446.1) & $94 \%$ & $1(3.3 \%)$ \\
\hline & Afipia sp. (AB586143.1) & $99 \%$ & $1(3.3 \%)$ \\
\hline & Pseudomonas sp. (MH428812.1) & $99 \%$ & $1(3.3 \%)$ \\
\hline Total & 30 & & \\
\hline
\end{tabular}

*Approximately 800 nucleotides were read. 
Table 2. Identification of clone library prepared from nonstarter MJ (14 days).

\begin{tabular}{|c|c|c|c|}
\hline Sample & $\begin{array}{l}\text { 16S rRNA gene sequence* } \\
\text { (NCBI Accession No.) }\end{array}$ & $\begin{array}{c}\text { Similarity } \\
(\%)\end{array}$ & $\begin{array}{c}\text { Clone } \\
\text { numbers } \\
\text { out of } \\
30(\%)\end{array}$ \\
\hline \multirow{18}{*}{ PS } & Variovorax sp. (MH698893.1) & $99 \%$ & $8(26.7 \%)$ \\
\hline & Uncultured bacterium (HM141889.1) & $99 \%$ & $6(20.0 \%)$ \\
\hline & Uncultured bacterium (FN567167.1) & $96 \%$ & $1(3.3 \%)$ \\
\hline & Uncultured bacterium (DQ451505.1) & $99 \%$ & $1(3.3 \%)$ \\
\hline & Uncultured bacterium (JX564435.1) & $94 \%$ & $1(3.3 \%)$ \\
\hline & Sphingopyxis sp. (KM670029.2) & $99 \%$ & $1(3.3 \%)$ \\
\hline & Sphingopyxis sp. (KX085480.1) & $99 \%$ & $1(3.3 \%)$ \\
\hline & Serratia marcescens (СР029715.1) & $99 \%$ & $1(3.3 \%)$ \\
\hline & Serratia marcescens (СР027798.1) & $99 \%$ & $1(3.3 \%)$ \\
\hline & Ralstonia sp. (HE575954.1) & $96 \%$ & $1(3.3 \%)$ \\
\hline & Ralstonia sp. (LC385700.1) & $100 \%$ & $1(3.3 \%)$ \\
\hline & Bradyrhizobium sp. (MG798777.1) & $98 \%$ & $1(3.3 \%)$ \\
\hline & Byrhizobium sp. (MG798777.1) & $92 \%$ & $1(3.3 \%)$ \\
\hline & Burkholderia lata (СР013406.1) & $100 \%$ & $1(3.3 \%)$ \\
\hline & Comamonas sp. (MH698867.1) & $99 \%$ & $1(3.3 \%)$ \\
\hline & Afipia sp. (JX963091.1) & $99 \%$ & $1(3.3 \%)$ \\
\hline & Acinetobacter sp. (FN395271.1) & $99 \%$ & $1(3.3 \%)$ \\
\hline & Sphingomonas sanxanigenens (AB649022.1) & $100 \%$ & $1(3.3 \%)$ \\
\hline \multirow[t]{5}{*}{ Total } & 30 & & \\
\hline & Uncultured bacterium (HM141889.1) & $99 \%$ & $19(63.3 \%)$ \\
\hline & Uncultured bacterium (GU455124.1) & $99 \%$ & $1(3.3 \%)$ \\
\hline & Afipia sp. (EU130950.1) & $99 \%$ & $3(10.0 \%)$ \\
\hline & Afipia sp. (JN697519.1) & $99 \%$ & $2(6.7 \%)$ \\
\hline \multirow[t]{5}{*}{ SS } & Afipia sp. (KU713085.1) & $99 \%$ & $1(3.3 \%)$ \\
\hline & Afipia lausannensis (DQ123622.1) & $99 \%$ & $1(3.3 \%)$ \\
\hline & Afipia massiliensis (NR_025646.1) & $100 \%$ & $1(3.3 \%)$ \\
\hline & Uncultured Afipia sp. (JN697519.1) & $100 \%$ & $1(3.3 \%)$ \\
\hline & Sphingomonas sanxanigenens (AB649022.1) & $99 \%$ & $1(3.3 \%)$ \\
\hline \multirow[t]{8}{*}{ Total } & 30 & & \\
\hline & Uncultured bacterium (HM1418 & $99 \%$ & $10(33.3 \%)$ \\
\hline & Uncultured bacterium (JF429287.1) & $99 \%$ & $1(3.3 \%)$ \\
\hline & Uncultured bacterium (DQ890427.1) & $97 \%$ & $1(3.3 \%)$ \\
\hline & Variovorax sp. (MH698893.1) & $100 \%$ & $2(6.7 \%)$ \\
\hline & Afipia sp. (JX963091.1) & $99 \%$ & $1(3.3 \%)$ \\
\hline & Afipia sp. (EU130950.1) & $99 \%$ & $1(3.3 \%)$ \\
\hline & Afipia massiliensis (KY319044.1) & $99 \%$ & $1(3.3 \%)$ \\
\hline \multirow[t]{8}{*}{ BS } & Bradyrhizobium sp. (СР025113.1) & $94 \%$ & $2(6.7 \%)$ \\
\hline & Bradyrhizobium sp. (MG798777.1) & $99 \%$ & $2(6.7 \%)$ \\
\hline & Hyphomonas sp. (СР016437.1) & $94 \%$ & $3(10.0 \%)$ \\
\hline & Sphingopyxis macrogoltabida (СР012700.1) & $89 \%$ & $2(6.7 \%)$ \\
\hline & Serratia sp. (KF077052.1) & $94 \%$ & $1(3.3 \%)$ \\
\hline & Comamonas testosteroni (LC090503.1) & $98 \%$ & $1(3.3 \%)$ \\
\hline & Pseudomonas mendocina (СР010892.1) & $97 \%$ & $1(3.3 \%)$ \\
\hline & Rhodopseudomonas palustris (СР000463.1) & $91 \%$ & $1(3.3 \%)$ \\
\hline tan & & & \\
\hline
\end{tabular}

${ }^{*}$ Approximately 800 nucleotides were read. and Burkholderia sp. were the next abundant groups in PSMJ, both occupying $20 \%$ of a clone library (6 out of 30 ). Acidovorax sp. were also detected often from SSMJ (13.3\%) and BSMJ (20\%) clone libraries. The genus Acidovorax consists of Gram-negative bacteria belonging to the family of Comamonadaceae, the order of Burkholderiales, and of $\beta$-proteobacteria. Acidovorax sp. can be separated into 2 groups, phytopathogens and water and soil inhabitants [22]. Some Acidovorax sp. have been studied for their ability to degrade chemical pollutants such as arsenite, polychlorinated biphenyl, and 2-nitrotoluene [23, 24]. Burkholderia sp. were also detected often, occupying $20 \%$ (6 out of 20), $30 \%$ (9 out of 30 ), and $6.7 \%$ ( 2 out of 30 ) of PSMJ, SSMJ, and BSMJ clone libraries, respectively. Burkholderia sp. are widely distributed in various environments including soil, water, wastewater treatment systems, and plants [25]. Uncultured bacteria occupied $6.7 \%$ ( 2 out of 30 ), 3.3\% (1 out of 30 ), and $20 \%$ (6 out of 30 ) of PSMJ, SSMJ, and BSMJ clone libraries, respectively. Ralstonia sp. and Bradyrhizobiaceae sp. were detected twice $(6.7 \%)$ in the PSMJ clone library. Comanmonas sp. were detected twice (6.7\%) from the SSMJ clone library, and a Pseudomonas sp. was detected once (3.3\%) from the BSMJ clone library.

From MJ samples at day 14, uncultured bacteria were the major group, occupying $30 \%, 66.7 \%$, and $40 \%$ of the PSMJ, SSMJ, and BSMJ clone libraries, respectively (Table 2). In the PSMJ clone library, Variovorax sp. were the next dominant (8 out of 30,26.7\%), and Serratia sp., Ralstonia sp., and Bradyrhizobium sp. were detected twice (6.7\%). In the SSMJ clone library, Afipia sp. were the second dominant (8 out of 30,26.7\%). Afipia is a genus Gram-negative and nonfermentative rod-shaped bacteria belonging to the family Bradyrhizobiaceae, $\alpha$-proteobacteria. Afipia sp. are studied for their ability to degrade toxic chemicals such as 1,4-dioxane [26]. In the BSMJ clone library, Bradyrhizoboum sp. were the second dominant (4 out of 30,13.3\%), and Afipia sp. and Hyphomonas sp. were detected 3 times (10\%).

From MJ samples at day 28, Acidovorax sp. were the most dominant, occupying $80 \%, 40 \%$, and $73.3 \%$ of PSMJ, SSMJ, and BSMJ clone libraries, respectively (Table 3). Uncultured bacteria were the second most dominant. Burkholderia sp. were detected 3 times (10\%) from BSMJ clone library, and once each from PSMJ and SSMJ clone libraries. Afipia sp. were observed from MJ samples at day 0 and 14, but not at 28 .

LAB, Lactobacillus sakei and Streptococcus sp., were detected from PSMJ and SSMJ clone libraries at day 28. LAB occupied 30\% (L. sakei 16.7\%, Streptococcus sp. 13.3\%) of the SSMJ clone library and $3.3 \%$ of the PSMJ clone library, but were not detected from BSMJ. It seemed that environments 
Table 3. Identification of clone library prepared from nonstarter MJ (28 days).

\begin{tabular}{|c|c|c|c|}
\hline Sample & $\begin{array}{l}\text { 16S rRNA gene sequence } \\
\text { (NCBI Accession No.) }\end{array}$ & $\begin{array}{l}\text { Similarity } \\
(\%)\end{array}$ & $\begin{array}{c}\text { Clone } \\
\text { numbers } \\
\text { out of } \\
30(\%)\end{array}$ \\
\hline \multirow{8}{*}{ PS } & Acidovorax sp. (MH512862.1) & $100 \%$ & $22(73.3 \%)$ \\
\hline & Acidovorax sp. (AY093698.1) & $100 \%$ & $1(3.3 \%)$ \\
\hline & Acidovorax sp. (KT354276.1) & $100 \%$ & $1(3.3 \%)$ \\
\hline & Bacterium enrichment (KC979079.1) & $98 \%$ & $2(6.7 \%)$ \\
\hline & Ralstonia sp. (MH144298.1) & $98 \%$ & $1(3.3 \%)$ \\
\hline & Ralstonia sp. (LC385700.1) & $99 \%$ & $1(3.3 \%)$ \\
\hline & Burkholderia lata (СР013406.1) & $100 \%$ & $1(3.3 \%)$ \\
\hline & Streptococcus parasanguis (AM157421.1) & $100 \%$ & $1(3.3 \%)$ \\
\hline \multirow[t]{5}{*}{ Total } & 30 & & \\
\hline & Acidovorax sp. (MH512862.1) & $100 \%$ & $12(40.0 \%)$ \\
\hline & Uncultured bacterium (KM852123.1) & $99 \%$ & $5(16.7 \%)$ \\
\hline & Uncultured bacterium (HM141889.1) & $100 \%$ & $2(6.7 \%)$ \\
\hline & Lactobacillus sakei (СР032652.1) & $99 \%$ & $4(13.3 \%)$ \\
\hline \multirow[t]{5}{*}{ SS } & Lactobacillus sakei (AB362606.1) & $99 \%$ & $1(3.3 \%)$ \\
\hline & Streptococcus pyogenes (LS483331.1) & $100 \%$ & $2(6.7 \%)$ \\
\hline & Streptococcus pyogenes (CP022206.1) & $100 \%$ & $2(6.7 \%)$ \\
\hline & Burkholderia cepacia (LC420066.1) & $99 \%$ & $1(3.3 \%)$ \\
\hline & Piscinibacter sp. (KU233249.1) & $100 \%$ & $1(3.3 \%)$ \\
\hline \multirow[t]{4}{*}{ Total } & 30 & & \\
\hline & Acidovorax sp. (MH512862.1) & $100 \%$ & $22(73.3 \%)$ \\
\hline & Uncultured bacterium (KF515167.1) & $99 \%$ & $2(6.7 \%)$ \\
\hline & Uncultured bacterium (KM852123.1) & $99 \%$ & $1(3.3 \%)$ \\
\hline \multirow[t]{4}{*}{ BS } & Uncultured bacterium (KU973397.1) & $99 \%$ & $1(3.3 \%)$ \\
\hline & Uncultured bacterium (KR110096.1) & $100 \%$ & $1(3.3 \%)$ \\
\hline & Burkholderia cepacia (LC420066.1) & $99 \%$ & $2(6.7 \%)$ \\
\hline & Burkholderia lata (СР013406.1) & $99 \%$ & $1(3.3 \%)$ \\
\hline Total & 30 & & \\
\hline
\end{tabular}

*Approximately 800 nucleotides were read.

favoring the growth of LAB were developed in SSMJ around day 28 , and solar salt might encourage the growth of LAB. The appearance of LAB might cause changes in $\mathrm{pH}$ and TA of MJ samples. $\mathrm{pH}$ values decreased at day 21 and TA values increased rapidly from day 21 until day 28 (Fig. 3). In a previous report, bacterial communities of commercial jeotgal varieties made with myeolchi (anchovy), meongge (common sea squirt), and saeu (small shrimp) were analyzed by pyrosequencing of the V1-V2 region of $16 \mathrm{~S}$ rRNA genes [27]. L. sakei was the predominant bacterial species (50.7\%, average relative abundance) of 5 types of meongge jeotgal purchased at 4 different cities on the east and south coasts in Korea. Lactobacillus curvatus (15.8\%) and Weissella koreensis (8\%) were the next dominant species. The results matched with our observation of SSMJ at day 28. LAB, especially L. sakei, seemed an important member of the bacterial community in MJ fermentation. But it should be mentioned that the 5 commercial meongge jeotgal samples were quite different from ours. The average $\mathrm{NaCl}$ concentration was $4.6 \%$, much lower than our samples $(12 \%)$. Also, the average $\mathrm{pH}$ was 4.4 which was also lower than those of ours. The $\mathrm{pH}$ of PSMJ and SSMJ was 5.4-5.5 at day 42 (Fig. 3). Commercial meongge jeotgal products used for the previous study were most likely fermented for just a few days considering their low salt contents. The procedures of fermentation were also unknown. Because of high salinity and low temperature $\left(10^{\circ} \mathrm{C}\right), \mathrm{LAB}$ grew slowly in our MJ samples, and this explained the low LAB counts and higher $\mathrm{pH}$ values of our samples. At day $0, \mathrm{LAB}$ counts of our non-starter MJ samples were $9.50 \times 10^{2}-$ $5.75 \times 10^{3} \mathrm{CFU} / \mathrm{g}$, and the numbers decreased to $1 \times$ $10^{1} \mathrm{CFU} / \mathrm{g}$ at day 42 . But LAB counts of 5 commercial samples were $3.9 \times 10^{6}-6.5 \times 10^{7} \mathrm{CFU} / \mathrm{g}$ [27]. Unlike previous studies, Tetragenococcus sp. were not detected from our MJ samples up to day 28. In a previous study, fish sauce was prepared from deep sea smelt $(15 \% \mathrm{NaCl}, \mathrm{w} / \mathrm{w})$ and fermented at room temperature for 8 months [13]. When bacterial communities were analyzed by clone library (the same method used by us), Staphylococcus sp. were the dominant group until 4 weeks, and then T. halophilus became the most dominant species [13]. In our study, Staphylococcus sp. and Tetragenococcus sp. were not detected up to day 28. It was possible that Tetragenococcus sp. might appear in MJ samples after day 28 considering the low temperature $\left(10^{\circ} \mathrm{C}\right)$. In another study with commercial galchi jeotgal and myeolchi jeotgal, T. halophilus, T. muriaticus, and Lactobacillus sakei were the predominant species determined by PCR-DGGE method [28]. Salinities of these jeotgal types were very high, 30-48\% for galchi jeotgal and $26-40 \%$ for myeolchi jeotgal. Again, the exact fermentation conditions were unknown for these commercial products. In another study, kimchi samples were prepared with different jeotgal and their LAB were compared by culture independent method [29]. L. sakei was the dominant LAB in a kimchi with saeu jeotgal and T. halophilus was the dominant in kimchi with myeolchi jeotgal. The results indicate that growth of LAB in kimchi is affected by the particular jeotgal type added into kimchi.

One question to be answered was that bacilli were not detected from our MJ samples by culture-independent 
method. Bacilli counts of non-starter MJ samples were $5.52 \times 10^{2}-1.42 \times 10^{5} \mathrm{CFU} / \mathrm{g}$ throughout fermentation. It was suspected that universal primers (27F and 1492R) used were not efficient for amplification of $16 \mathrm{~S}$ rRNA genes from bacilli. Kim et al. reported that bacilli were not detected from doenjang samples by PCR-DGGE where 16S rRNA genes were first amplified by universal primers (27F and 1492R) followed by a second nested PCR using internal primers (338F and 518R) [30]. Bands specific for bacilli were only detected when a second nested PCR was done by using bacilli specific primers [30]. Fukui et al. also reported similar results [13]. Bacilli were not detected from fish sauce prepared from deep sea smelt by $16 \mathrm{~S}$ rRNA gene clone library method where $27 \mathrm{~F}$ and $1492 \mathrm{R}$ primers were used, but detected by cultural methods. These results showed that 16S rRNA genes of bacilli were poorly amplified with universal primers (27F and 1492R), which was confirmed by our results. Therefore, care must be exercised when community analysis is planned by cultureindependent method.

We used cultural method to isolate bacilli from MJ samples which were taken out at day 28 and frozen at $-70^{\circ} \mathrm{C}$. MJ samples were thawed and diluted with $0.1 \%$ peptone water and then spreaded onto marine agar (Difco, USA, $2.5 \% \mathrm{NaCl}$ ) and MRS agar plates. Colonies were picked up and 16S rRNA genes were amplified by using $27 \mathrm{~F}$ and $1492 \mathrm{R}$ universal primers. Sequencing results showed that bacilli were the most dominant group, occupying $50 \%$ (15 out of 30 ), $66.7 \%$ (20 out of 30 ), and $80 \%$ (24 out of 30) of 30 sequenced colonies on marine agar from PSMJ, SSMJ and BSMJ, respectively (Table S1). Not many colonies appeared on MRS agar plates. Enterococcus faecium and Staphyococcus epidermidis were identified together with bacilli (Table S2). The MJ samples were stored at $-70^{\circ} \mathrm{C}$, and this may have caused significant death of bacteria. Our results clearly show that culture-independent method should be used together with cultural method for accurate community analysis.

In previous studies on bacterial communities of commercial jeotgal, communities at a certain stage of fermentation were examined. No information on the changes in bacterial communities can be obtained from such purchased products. In this respect, our work provided for the first time some useful hints on the changes in bacterial communities of MJ samples during fermentation under a specific condition $\left(12 \%\right.$ salt and $\left.10^{\circ} \mathrm{C}\right)$. It became clear that bacterial community is affected by many factors including the nature of main materials, salt concentration, salt type, temperature, and other environmental factors.

The 2 dominant groups, Acidovorax sp. and LAB, were likely to play some roles in the fermentation of MJ, especially in SSMJ around day 28. Although no studies on the roles of Acidovorax sp. (or any other group) for jeotgal fermentations have been reported, results obtained through this work are interesting and show the need for future studies. Although just 30 clones from each MJ sample were examined, the results still showed significant differences in bacterial species among MJ samples prepared with different types of salts. Since each salt type has different components, and bacteria such as LAB respond to specific components, difference in bacterial community (and quality of fermented foods) can be expected [31]. Future studies on the roles of Acidovorax sp. and other groups identified through this work are necessary. Studies should include isolation of these organisms by cultural methods, characterization of properties of these groups, and identification of major metabolites produced by them. Also, more studies are required to confirm the effects of solar salt on the growth of LAB during MJ fermentation.

Table 4. Sensory evaluation results of meongge jeotgal samples at day 28.

\begin{tabular}{|c|c|c|c|c|c|c|}
\hline \multirow{2}{*}{ After 28 days } & \multicolumn{3}{|c|}{ Starter } & \multicolumn{3}{|c|}{ Non-starter } \\
\hline & PS & SS & BS & PS & SS & BS \\
\hline Color & $4.19 \pm 0.87^{c}$ & $3.67 \pm 0.66^{c}$ & $2.86 \pm 0.96^{b}$ & $3.81 \pm 1.08^{c}$ & $3.76 \pm 1.04^{c}$ & $2.24 \pm 1.14^{\mathrm{a}}$ \\
\hline Flavor & $3.19 \pm 0.81^{\mathrm{ab}}$ & $3.57 \pm 1.12^{\mathrm{b}}$ & $2.86 \pm 1.28^{\mathrm{ab}}$ & $3.00 \pm 1.05^{\mathrm{ab}}$ & $3.33 \pm 1.02^{\mathrm{b}}$ & $2.57 \pm 0.98^{\mathrm{a}}$ \\
\hline Texture & $3.86 \pm 0.79^{\mathrm{bc}}$ & $4.10 \pm 0.70^{\mathrm{cd}}$ & $2.76 \pm 0.83^{\mathrm{a}}$ & $3.71 \pm 0.85^{\mathrm{bc}}$ & $3.38 \pm 0.86^{\mathrm{b}}$ & $3.33 \pm 0.73^{b}$ \\
\hline Saltiness & $2.86 \pm 1.28^{\mathrm{bc}}$ & $3.33 \pm 0.86^{c}$ & $2.43 \pm 1.36^{\mathrm{ab}}$ & $2.33 \pm 1.20^{\mathrm{ab}}$ & $3.00 \pm 1.05^{\mathrm{bc}}$ & $2.00 \pm 1.22^{\mathrm{a}}$ \\
\hline Fishy smell & $3.10 \pm 1.30^{b}$ & $2.81 \pm 0.87^{\mathrm{ab}}$ & $2.38 \pm 1.02^{\mathrm{a}}$ & $2.90 \pm 0.94^{\mathrm{ab}}$ & $3.19 \pm 0.81^{b}$ & $2.33 \pm 1.02^{\mathrm{a}}$ \\
\hline Umami & $3.24 \pm 0.70^{\mathrm{bc}}$ & $3.43 \pm 1.08^{\mathrm{bc}}$ & $2.81 \pm 0.81^{\mathrm{ab}}$ & $3.48 \pm 1.12^{c}$ & $3.43 \pm 1.03^{\mathrm{bc}}$ & $2.57 \pm 0.93^{\mathrm{a}}$ \\
\hline Overall acceptability & $3.29 \pm 0.72^{\mathrm{b}}$ & $3.48 \pm 1.21^{\mathrm{b}}$ & $2.48 \pm 1.08^{\mathrm{a}}$ & $3.19 \pm 0.93^{\mathrm{b}}$ & $3.43 \pm 0.68^{\mathrm{b}}$ & $2.48 \pm 1.03^{\mathrm{a}}$ \\
\hline
\end{tabular}

*Significant difference between the values in the same tested items $(p<0.005$, by least significant difference test). 


\section{Sensory Evaluation}

Sensory evaluation was done for MJ samples at day 28 (Table 4). SSMJ (non-starter and starter) received the highest scores for flavor, and the overall acceptability scores were also higher than those of other MJ samples. BSMJ samples got lower scores than other types of MJ. This might be related to differences in bacterial communities among $\mathrm{MJ}$ samples. For example, LAB were not detected from BSMJ. LAB are the most important group of microorganisms for various fermented foods by producing acids, amino acids, peptides, and other metabolites positively affecting the quality of fermented foods [32]. In this respect, solar salt has an advantage over PS and BS for MJ fermentation by encouraging growth of LAB. These effects might be the major reason for the better sensory properties of SSMJ samples. Further studies are necessary to characterize the responsible compounds present in SS. If the compounds are identified, they could be used to improve the sensory properties of MJ products. The results obtained through this work can be applied to other fermented foods where salt is an important component. Use of solar salt instead of purified salt and bamboo salt can cause changes in microbial community of a specific food, which can positively affect the quality of the corresponding food.

\section{Acknowledgments}

This study was supported by grant 20130290 to the Solar Salt Research Center of Mokpo, National University, from the Ministry of Oceans and Fisheries, Korea. J. A Kim and Z. Yao were also supported by the BK21 Plus Program from the Ministry of Education, Korea.

\section{Conflict of Interest}

The authors have no financial conflicts of interest to declare.

\section{References}

1. Heu MS, Kim JH, Kim MJ, Lee JS, Kim KH, Kim HJ, et al. 2013. Taste, nutritional and functional characterizations of commercial seasoned sea squirt Halocynthia roretzi. Kor. J. Fish Aquat. Sci. 46: 18-26.

2. Kim JH, Kim MJ, Lee JS, Kim KH, Kim HJ, Heu MS, et al. 2013. Development and characterization of sea squirt Halocynthia roretzi sikhae. Kor. J. Fish Aquat. Sci. 46: 27-36.

3. Kim PH, Kim MJ, Kim JH, Lee JS, Kim KH, Kim HJ, et al. 2014. Nutritional and physiologically active characterization of the sea squirt Halocynthia roretzi sikhae and the seasoned sea squirt. Kor. J. Fish Aquat. Sci. 47: 1-11.

4. Koo OK, Lee SJ, Chung KR, Jang DJ, Yang HJ, Kwon DY. 2016. Korean traditional fermented fish products: jeotgal. J. Ethn. Foods 3: 107-116.

5. Chang JY, Kim IC, Chang HC. 2011. Effect of solar salt on the fermentation characteristics of kimchi. Korean J. Food Preserv. 18: 256-265.

6. Kim SH, Kim SJ, Kim BH. 2000. Fermentation of doenjang prepared with sea salts. Korean J. Food Sci. Technol. 32: 13651370.

7. Shim JM, Lee KW, Yao Z, Kim JA, Kim HJ, Kim JH. 2017. Microbial communities and physicochemical properties of myeolchi jeotgal (anchovy jeotgal) prepared with different types of salts. J. Microbiol. Biotechnol. 27: 1744-1752.

8. Lee KW, Shim JM, Kim DW, Yao Z, Kim JA, Kim HJ, et al. 2018. Effects of different types of salts on the growth of lactic acid bacteria and yeasts during Kimchi fermentation. Food Sci. Biotechnol. 27: 489-498.

9. Yao Z, Kim JA, Kim JH. 2018. Properties of a fibrinolytic enzyme secreted by Bacillus subtilis JS2 isolated from saeu (small shrimp) jeotgal. Food Sci. Biotechnol. 27: 765-772.

10. Kim JA, Yao Z, Perumal V, Kim HJ, Kim JH. 2018. Properties of Tetragenococcus halophilus strains isolated from myeolchi (anchovy)-jeotgal. Microbiol. Biotechnol. Lett. 46: 313-319.

11. Zhao X, Jung OS, Park KY. 2012. Alkaline and antioxidant effects of bamboo salt. J. Korean Soc. Food Sci. Nutr. 41: 13011304.

12. Jung JY, Lee SH, Lee HJ, Jeon CO. 2013. Microbial succession and metabolic changes during fermentation of saeu-jeot: traditional Korean salted seafood. Food Microbiol. 34: 360-368.

13. Fukui $Y$, Yoshida M, Shozen K, Funatsu Y, Takano T, Oikawa $\mathrm{H}$, et al. 2012. Bacterial communities in fish sauce mash using culture-dependent and -independent methods. J. Gen. Appl. Microbiol. 58: 273-281.

14. Lee KD, Choi CR, Cho JY, Kim HL, Ham KS. 2008. Physicochemical and sensory properties of salt-fermented shrimp prepared with various salts. J. Korean Soc. Food Sci. Nutr. 37: 53-59.

15. Zhao CJ, Schieber A, Gänzle MG. 2016. Formation of tasteactive amino acids, amino acid derivatives and peptides in food fermentations-a review. Food Res. Int. 89: 39-47.

16. Oh SH, Sung TH, Heo OS, Bang OK, Chang HC, Shin HS, et al. 2004. Physocochemical and sensory properties of commercial salt-fermented shrimp. J. Korean Soc. Food Sci. Nutr. 33: 1006-1012.

17. Hwang SM, Kim YA, Ju JC, Lee SJ, Choi JD, Oh KS. 2011. Volatile flavor constituents of the low-salt fermented Ascidian. J. Agric. Life Sci. 45: 141-150.

18. Satola B, Wübbeler JH, Steinbüchel A. 2013. Metabolic characteristics of the species Variovorax paradoxus. Appl. Microbiol Biotechnol. 97: 541-560. 
19. Robertson AW, McCarville NG, Maclntyre LW, Correa $\mathrm{H}$, Haltli B, Marchbank DH, et al. 2018. Isolation of imaqobactin, an amphiphilic siderophore from the Arctic marine bacterium Variovorax Species RKJM285. J. Nat. Prod. 81: 858-865.

20. Han JI, Cho HK, Lee SW, Orwin PM, Kim J, LaRoe SL, et al. 2011. Complete genome sequence of the metabolically versatile plant growth-promoting endophyte Variovorax paradoxus S110 J. Bacteriol. 193: 1183-1190.

21. Yoon JH, Kang SJ, Oh TK. 2006. Variovorax dokdonensis sp. nov., isolated from soil. Int. J. Syst. Evol. Microbiol. 56: 811814.

22. Boycheva SS, Pichler FB, Heijstra BD, Lau KEM, Turner SJ. 2015. The genetic toolbox for Acidovorax temperans. J. Microbiol. Methods 115: 129-138.

23. Huang Y, Li H, Rensing C, Zhao K, Johnstone L, Wang G. 2012. Genome sequence of the facultative anaerobic arseniteoxidizing and nitrate-reducing bacterium Acidovorax sp. strain NO1. J. Bacteriol. 194: 1635-1636.

24. Lee KS, Parales JV, Friemann R, Parales RE. 2005. Active site residues controlling substrate specificity in 2-nitrotoluene dioxygenase from Acidovorax sp. strain JS42. J. Ind. Microbiol. Biotechnol. 32: 465-473.

25. Lee JW, Kim YE, Park SJ. 2018. Burkholderia alba sp. nov., isolated from a soil sample on Halla mountain in Jeju island. J. Microbiol. 56: 312-316.

26. Isaka K, Udagawa M, Sei K, Ike M. 2016. Pilot test of biological removal of 1,4-dioxane from a chemical factory wastewater by gel carrier entrapping Afipia sp. strain D1. J. Hazard Mater. 304: 251-258.

27. Song EJ, Lee ES, Park SL, Choi HJ, Roh SW, Nam YD. 2018. Bacterial community analysis in three types of the fermented seafood, jeotgal, produced in south Korea. Biosci. Biotechnol. Biochem. 82: 1444-1454.

28. Lee Y, Cho Y, Kim E, Kim HJ, Kim HY. 2018. Identification of lactic acid bacteria in galchi- and myeolchi-jeotgal by $16 \mathrm{~S}$ rRNA gene sequencing, MALDI-TOP mass spectrometry, and PCR-DGGE. J. Microbiol. Biotechnol. 28: 1112-1121.

29. Jung MY, Kim TW, Lee C, Kim JY, Song HS, Kim YB, et al. 2018. Role of jeotgal, a Korean traditional fermented fish sauce, in microbial dynamics and metabolite profiles during kimchi fermentation. Food Chem. 265: 135-143.

30. Kim TW, Lee JH, Kim SE, Park MH, Chang HC, Kim HY. 2009. Analysis of microbial communities in doenjang, a Korean fermented soybean paste, using nested PCR-denaturing gradient gel electrophoresis. Int. J. Food Microbiol. 131: 265271.

31. Kim DW, Kim BM, Lee HJ, Jang GJ, Song SH, Lee JI, et al. 2017. Effects of different salt treatments on the fermentation metabolites and bacterial profiles of kimchi. J. Food Sci. 82: 1124-1131.

32. Raveschot C, Cudennec B, Coutte F, Flahaut C, Fremont M, Drider D, et al. 2018. Production of bioactive peptides by Lactobacillus species: from gene to application. Front. Microbiol. 9: 2354 . 